\title{
El Archivo fotográfico CECA-Cecabank
}

MEI

II, vol. 5

$\mathrm{n}^{0} 9$

\author{
María Jesús del Río Álvarez \\ Sandra Fresnillo del Saz \\ Cecabank servicios financieros
}

Recibido el 24-09-2014 Aceptado en 14-11-2014

\section{Resumen}

El Archivo Fotográfico de CECA-Cecabank posee una amplia y destacable colección de imágenes que cronológicamente abarca desde 1923 hasta la actualidad. A lo largo del artículo se realiza un repaso a la historia del Archivo Histórico de CECA-Cecabank y al origen de los fondos fotográficos, se analiza también su tratamiento, conservación, acceso y difusión. Se pretende resaltar el valor de estas fotografías como documentos visuales fundamentales para la historia de las Cajas de Ahorros, de la Obra Social de estas entidades y de la CECA como parte esencial de la historia financiera de España.

\section{Palabras clave}

Confederación Española de Cajas de Ahorros (CECA); Cajas de Ahorros; Obra Social; historia económica; archivos bancarios; archivos históricos; archivos fotográficos.

\section{Title}

The CECA-Cecabank Photographic archive

\begin{abstract}
The Photographic Archive of CECA-Cecabank has an extensive and remarkable collection of images that chronologically covers from 1923 to present-day. Throughout the article, a review is made to the history of the Historical Archive of CECA-Cecabank and the origin of the photographic collection; it is also analyzed its processing, storage, access and diffusion. It is intended to highlight the value of these photographs as visual documents fundamental for the history of the Savings Banks, the Social Work of these entities and CECA, as an essential part of the financial history of Spain.

\section{Keywords}

Spanish Confederation of Savings Banks (CECA); Savings Banks; Social Work; economic history; bank archives; historical archives; photographic archives.
\end{abstract}




\section{1.- Introducción}

La reestructuración del sector Cajas de Ahorros ha supuesto para el Archivo Histórico de la Confederación Española de Cajas de Ahorros (CECA), actualmente Archivo Histórico de CECA-Cecabank, una mayor inquietud en temas de salvaguarda del patrimonio histórico documental vinculado a estas entidades.

Si en su origen la finalidad principal del Archivo Histórico de CECACecabank era fundamentalmente la de servir a la propia entidad como custodio de todos los documentos calificados como de conservación permanente con el objetivo de proteger su memoria histórica, ahora será también la de promover iniciativas de conservación de la numerosa documentación que posee en su depósito vinculada a la historia de las Cajas de Ahorros en España.

El Archivo Histórico de CECA-Cecabank se engloba dentro de la categoría de archivo bancario y como tal ofrece información de considerable interés para la historia de la entidad, para la historia financiera y para la historia en general de España desde diversos aspectos. Los archivos bancarios "nos muestran como se han financiado industrias y empresas en general, de dónde han obtenido el dinero para sus inversiones, pero además nos ilustran también sobre importantes aspectos de la vida política, cultural...” (Tortella, 1989).

A nivel nacional el interés por los archivos bancarios es mucho más reciente que el que ha podido existir sobre otros tipos de archivo. En los años ochenta el único archivo bancario con los fondos realmente accesibles al público investigador era el Archivo del Banco de España, abierto al público el 2 de junio de 1982 (Tortella, 1983). Desde entonces y hasta la actualidad muchos archivos bancarios han vivido una precaria situación determinada en muchos casos por la falta de personal cualificado y la ausencia de legislación. En fechas más próximas se constituyen los archivos bancarios de otras entidades financieras como el Archivo Histórico del Banco Santander y el Archivo Histórico del BBVA que han impulsado acciones para su consolidación.

En el caso de las Cajas de Ahorros durante los años setenta se publicaron diversos estudios sobre la gestión de sus archivos a través del Boletín de Documentación del Fondo para la Investigación Económica y Social (FIES), actual Fundación de las Cajas de Ahorros (FUNCAS), que parecían impulsar su puesta en valor y fomentar iniciativas orientadas a la consolidación de los mismos tratando sobre temas diversos como la creación de un sistema decimal universal (Lasso-de-la-Vega, 1971) o fondos custodiados, tal fue el caso del Archivo Histórico de la Caja de Ahorros y Monte de Piedad de Madrid (Vellosillo, 1970). 
En la actualidad, la situación es muy diferente, se tiene conocimiento de algunos de estos archivos como, por ejemplo, del Archivo Histórico de Caja España (Carriedo, 2008), del Archivo Unicaja y del Archivo Histórico de Bancaja (Bancaixa, 2011). No obstante, se ha perdido la pista de otros archivos históricos vinculados a las Cajas de Ahorros, tal sea el ejemplo del Archivo Histórico de la Caja de Ahorros del Mediterráneo (CAM) y su Proyecto Raíces (CAM, 2005). La no existencia real de estos archivos o el desconocimiento originado por la falta de difusión de los mismos, lleva al Archivo Histórico de CECACecabank a la necesidad de generar acciones que velen por la conservación del patrimonio histórico documental asociado a la historia de la CECA y de las Cajas de Ahorros, tema que desde hace tiempo es considerado de gran relevancia debido a la aportación de los fondos documentales de las Cajas de Ahorros y de los Montes de Piedad a la historia social y económica de España (TitosMartínez, 1976).

El Archivo Histórico está inmerso actualmente en promover y potenciar una de estas acciones, en concreto pretende crear un Archivo Fotográfico de la CECA y del sector Cajas de Ahorros que permita resaltar el valor de las fotografías como documentos visuales fundamentales, a nivel nacional e internacional, para conocer la historia de estas entidades, de su Obra Social y de la CECA como parte esencial de la historia financiera de España.

El fondo fotográfico comienza a formarse en 2007 con la creación del Archivo Histórico pero al llegar finales de 2011 se toma conciencia de que el volumen que abarca es muy reducido por lo que a partir de esa fecha se inicia un plan de acción para localizar y seleccionar aquellas fotografías que por su valor histórico debían conservarse permanentemente. Tras esta labor inicial se alcanza la cifra de 15.000 imágenes en diversos formatos y de distintas temáticas.

Ante la cantidad de imágenes de considerable valor que se localiza en esta fase inicial, al Archivo Histórico se le plantean diversos retos en la creación y gestión del futuro Archivo Fotográfico, entre los que se encuentran: la catalogación de los fondos fotográficos, la consolidación de un proyecto de digitalización, la conservación de la colección y su difusión.

"La calidad de una colección o fondo fotográfico no la proporciona el volumen de documentos ni el carácter de los soportes, sino la presencia de elementos que aporten información y sean capaces de promover conocimiento. Cuando se habla de fotografía hay una cierta tendencia a pensar que lo más valioso son las imágenes en sí mismas, pero lo que pone en valor esta documentación es la información que contienen y el contexto comunicativo en el que se enmarcan” (Sánchez-Vigil y Salvador-Benítez, 2013).

El objetivo de este artículo es dar a conocer las iniciativas que el Archivo 
Histórico de CECA-Cecabank está llevando a cabo sobre su fondo fotográfico para crear el Archivo Fotográfico de la CECA y del sector Cajas de Ahorros.

\section{2.- La Confederación Española de Cajas de Ahorros (CECA)}

Para valorar los fondos custodiados en el Archivo Histórico de CECACecabank es necesario conocer el origen y el papel que la CECA ha representado en la historia del sector Cajas de Ahorros.

La CECA nació en 1928 como ente asociativo de este tipo de entidades. A lo largo de más de 85 años, la historia de esta institución revela una importante y eficaz labor a favor de las Cajas, una lucha por la defensa del ahorro y una destacada aportación al éxito que en el pasado tuvieron estas entidades (ComínComín, 2008).

Esta asociación fue el "instrumento" que utilizaron las Cajas de Ahorros para facilitar la cooperación entre ellas, fue un foro para compartir experiencias, buscar soluciones a problemas y retos y debatir numerosos temas. Al mismo tiempo, la CECA fue el canal e intermediario entre las Cajas de Ahorros y las autoridades económicas nacionales e internacionales, y al revés, pero siendo siempre estas entidades independientes y autónomas en su acción y toma de decisiones.

Actualmente y con la reestructuración del sector, existe también Cecabank que es el banco a través del cual la CECA realiza el ejercicio indirecto de su actividad financiera como entidad de crédito. Con la nueva estructura, los órganos de gobierno de la CECA siguen tomando las decisiones de índole asociativa, en defensa de los intereses de sus entidades adheridas (Cajas de Ahorros y bancos de Cajas) y asociadas (fundaciones), y los del nuevo banco, Cecabank, se ocupan de la actividad prestadora de servicios.

\section{3.- El Archivo Histórico de CECA-Cecabank}

\section{1.- Origen y Funciones}

El Archivo Histórico de la CECA nace en 2007 y conserva una valiosa y extensa colección de fondos con documentos generados por las actividades realizadas por la CECA desde su creación en 1928 hasta la actualidad. El groso documental del Archivo Histórico es, por el momento, básica y fundamentalmente de la CECA, ya que Cecabank nació en 2012. 
El Archivo Histórico también representa con amplitud diversos aspectos del sector Cajas de Ahorros al poseer tanto documentación generada desde las propias entidades como documentación originada a partir de la relación de la CECA con sus asociadas.

El Archivo Histórico constituye una unidad de información dentro de la entidad y está considerado un pilar fundamental para la conservación de la memoria histórica de la CECA, en el futuro también de Cecabank, permitiendo comprender, por ejemplo, en qué contexto nació la asociación y cómo ha evolucionado o conocer que vínculos tiene o ha tenido con otras organizaciones $y$ entidades.

En la actualidad el archivo cuenta con más de 20.000 documentos, de los que 4.700 son públicos para su consulta.

En 2010 se creó la web del Archivo Histórico y en 2011 se abrió al público permitiendo a los investigadores la consulta en sala de los documentos no confidenciales, previa acreditación y justificación del objeto de la investigación. Desde esa fecha son numerosas las consultas que se reciben, a nivel nacional e internacional, sobre todo acerca de temas relativos a la historia de las Cajas de Ahorros.

Vinculados al Archivo Histórico existen una biblioteca y una hemeroteca. La Biblioteca cuenta con una importante colección de monografías sobre Cajas de Ahorros, historia de Cajas de Ahorros, Obra Social, Montes de Piedad, etc. y sistema financiero en general. La Hemeroteca es especializada e intenta recopilar a texto completo todos los artículos doctrinales sobre Cajas de Ahorros que se hayan publicado. Actualmente se dispone de más de 900 artículos que abarcan desde 1928 hasta el presente año.

\section{2.- Organización}

El Archivo Histórico se organiza en "secciones" que intentan asemejarse a series documentales y pueden corresponder a funciones, al organigrama o crearse con otros fines. Destacan el fondo de Memorias e Informes anuales de Cajas de Ahorros donde pueden encontrarse más de 3.500 documentos y el fondo fotográfico que permite un recorrido visual por la historia de la CECA y de las Cajas de Ahorros y que constituye el germen del futuro Archivo Fotográfico. 
Las secciones del archivo, por el momento, son las siguientes:

- Asambleas

- Consejos y Comités

- Escuela Superior de Cajas de Ahorros

- Concurso Hucha de Oro

- Promoción y Propaganda del Ahorro

- Gestión y Organización

- Historia económica

- Legislación

- Obra Social

- Montes de Piedad

- Dictámenes e Informes

- Memorias e Informes anuales de Cajas de Ahorros

- Estatutos y Reglamentos de Cajas de Ahorros

- Fondo fotográfico

- Congresos y Reuniones

\section{4.- El Archivo Fotográfico de CECA-Cecabank}

\section{1- Gestión del fondo fotográfico}

El fondo fotográfico depende del Archivo Histórico de CECA-Cecabank que es el responsable del tratamiento, conservación, accesibilidad y difusión del conjunto de los fondos documentales de la CECA y Cecabank.

La gestión del fondo fotográfico se realiza directamente por el personal del Archivo Histórico que vela por la organización y la custodia de la documentación que está bajo su responsabilidad con la finalidad de facilitar la consulta. El personal del archivo identifica y clasifica las fotografías, llevando un control de calidad de la información contenida.

El fondo fotográfico comienza a formarse con la creación del Archivo Histórico en el año 2007 dentro del seno del extinto Departamento de Documentación y Biblioteca. Hasta esa fecha la labor archivística no había sido desempeñada como tal pero se habían realizado durante años acciones dirigidas a la recopilación y selección de determinadas fotografías susceptibles de ser conservadas en un Archivo Histórico. Estas primordiales labores de compilación de imágenes son consideradas de gran valor y constituyen los cimientos del futuro Archivo Fotográfico. 
No obstante, no se comienzan a describir y clasificar los fondos fotográficos hasta noviembre de 2010 con la creación de una aplicación informática especifica que replica en la web pública del Archivo Histórico. En lo que respecta a la parte tecnológica, el personal colabora con los departamentos de la entidad dedicados a los sistemas de información en lo referente a la implementación y mantenimiento del sistema informático utilizado. Actualmente se utiliza como software Lotus Notes de IBM aunque se gestiona vía web desde la intranet de la entidad, para lo que simplemente es necesario un navegador.

En la fase inicial de catalogación de las fotografías, se decidió incorporar aquellas imágenes datadas en los primeros años de vida de la asociación, en concreto las fotografías en soporte papel que abarcaban el periodo de 1928 a las bodas de plata de la entidad, componiendo una colección fotográfica muy reducida que sólo constaba de aproximadamente setenta imágenes. Una pequeña selección de estas fotografías iniciales fue digitalizada por el propio personal del archivo y puesta a disposición del público a través de su web.

En el año 2011, el Departamento de Documentación y Biblioteca es absorbido por el Departamento de Gestión del Conocimiento que aglutinará, entre otras funciones, los servicios de Centro de Documentación, Biblioteca y Archivo Histórico.

Tras la anexión del Archivo Histórico a este departamento, se realiza una evaluación del estado del archivo y se determinan nuevos criterios de actuación. Además se establecen las normas de organización y funcionamiento del Archivo Histórico así como las políticas de acceso y consulta y las condiciones de reproducción y préstamo.

El nuevo plan de acción supuso el impulso de una minuciosa y laboriosa función de localización y selección de fotografías, procedentes de los distintos departamentos de la entidad, que por su valor histórico debían ser incorporadas al fondo fotográfico. Esta labor supuso un incremento notable de los fondos y aun continúa en activo.

Actualmente y todavía en pleno proceso de identificación y descripción de gran parte de la colección, se han podido rescatar para su incorporación al futuro Archivo Fotográfico más de 15.000 fotografías en distintos soportes: papel, digital, diapositivas y negativos, y de diversos periodos de la historia de la CECA y de las Cajas de Ahorros, se recogen imágenes desde los primeros años veinte hasta la actualidad. En el caso de las Cajas de Ahorros sobre todo son imágenes procedentes de la actividad de la Obra Social.

El Archivo Histórico, consciente de que toda la colección no puede ser digitali- 
zada, lo que impide el conocimiento de gran parte del fondo, y que es necesaria una mayor visibilidad, decide aceptar la propuesta de la Universitat Politècnica de Valencia para figurar en su proyecto dFoto (Gato-Gutiérrez et al., 2011) definido como un directorio de archivos y colecciones de fotografía, tanto públicas como privadas, que sirve de instrumento de difusión del patrimonio fotográfico español, tanto histórico como contemporáneo.

Otra de las acciones llevadas a cabo por el nuevo departamento consistió en fijar los objetivos de conservación necesarios para todos los fondos del Archivo Histórico ya que hasta el momento no habían sido establecidos. En el caso del fondo fotográfico se estudian mejoras en su conservación para lo que se evalúa la creación de un proyecto de digitalización que permita limitar al máximo la consulta de los originales con el fin de conseguir una mejor conservación de los mismos y, a posteriori, una mayor difusión a través de la web del Archivo Histórico.

A finales de octubre de 2014, se perfila dicho proyecto de digitalización que, realizado por una empresa especializada, pretende alcanzar el volumen inicial de 1.000 fotografías en una primera fase y otras 2.000 fotografías en una segunda fase. La digitalización debido a la situación delicada de parte del material se realizará a través de escáner cenital de alta resolución y como resultado se obtendrá una imagen matriz en formato TIFF y una imagen en formato JPEG que poder manipular. Con esta acción se intentan asentar definitivamente las bases para la creación del Archivo Fotográfico.

Respecto a la promoción y difusión del fondo fotográfico, la web del Archivo Histórico de CECA-Cecabank cuenta con una sección propia dedicada a dicho fondo llamada Fototeca donde se localiza una selección de imágenes con una breve descripción y datación.

Las fotografías también son utilizadas para la difusión del Archivo Histórico a través de la serie "CECA a través de su Archivo Histórico" que se elabora periódicamente y se distribuye a los empleados de la entidad a través de una herramienta interna de gestión del conocimiento. La serie recoge breves fragmentos de la historia de la CECA así como eventos relevantes de la historia del sector Cajas de Ahorros. Hasta la fecha se han elaborado veinticinco entregas.

- Bodas de Plata de la Confederación (1953)

- Cajas de Ahorros "bancarias"

- El diseño presentado por la CECA es elegido ganador para el nuevo símbolo de la Agrupación Europea de Cajas de Ahorros (1988)

- El Libro del Ahorro, editado por El Financiero en 1929

- El Libro del Ahorro: Caja de Ahorros y Monte de Piedad de Madrid 
- Folletos de Propaganda, Publicidad y Publicaciones (1966-1975)

- Himno al Ahorro

- Historia de un logo

- I Exposición Nacional del Ahorro

- II Congreso Internacional del Ahorro, primera asistencia de la CECAB (Londres, del 7 al 11 de octubre de 1929)

- Inauguración de la sede de la calle Alcalá 27

- Instituto de la Mujer que Trabaja de la Caja de Pensiones para la Vejez y de Ahorros de Barcelona

- La creación de la Comisión Permanente, antecesora del Consejo de Administración

- Medalla al Mérito en el Ahorro

- Memoria del Primer Ejercicio Social 1928

- Nacimiento de la revista Ahorro

- Personajes para la historia: Diego Medrano y Treviño, creador de las Cajas de Ahorros Españolas

- Personajes para la historia: Francisco Moragas, maestro y apóstol de la previsión social

- Primer edificio de la CECA y despachos

- Primeras circulares

- Promoción y propaganda del ahorro infantil. Huchas de la CECA

- Promoción y propaganda del ahorro. ¿Cómo eran las primeras exposiciones?

- Recuerdo de la estancia en Crevillente de D. Miguel Allué Escudero, Director General de la Confederación Española de Cajas de Ahorros Benéficas, el día 24 de marzo de 1972

- V Campaña Artística de Navidad de la Caja de Ahorros de Asturias - 1954

Respecto a la difusión externa, existe una serie titulada "Documento del mes del Archivo Histórico de CECA-Cecabank" que se publica en la web del Archivo Histórico en una sección específica para ello y se difunde a través de listas de distribución especializadas en archivística y documentación y de la cual se han elaborado, por el momento, nueve documentos.

- Documento del mes $n^{\circ}$ 1. CECA-Cecabank a través de su Archivo Histórico: Primer edificio de CECA y despachos (1928)

- Documento del mes nº 2. CECA-Cecabank a través de su Archivo Históri- 
co: Promoción y propaganda del ahorro infantil. Huchas de CECA

- Documento del mes n 3. CECA-Cecabank a través de su Archivo Histórico: Himno al Ahorro

- Documento del mes $n^{\circ}$ 4. CECA-Cecabank a través de su Archivo Histórico: I Exposición Nacional del Ahorro

- Documento del mes n ${ }^{\circ}$ 5. CECA-Cecabank a través de su Archivo Histórico: Nacimiento de la Revista Ahorro

- Documento del mes n ${ }^{\circ}$ 6. CECA-Cecabank a través de su Archivo Histórico: Memoria de su Primer Ejercicio Social. Año 1928

- Documento del mes n ${ }^{\circ}$ 7. CECA-Cecabank a través de su Archivo Histórico: Historia de un Logo 1928 - 2012

- Documento del mes no 8 CECA-Cecabank a través de su Archivo Histórico: Inauguración del edificio social de ICCA-CECAB en la calle Alcalá 27, Madrid (1947)

- Documento del mes no 9 CECA-Cecabank a través de su Archivo Histórico:

Inclusión de la enseñanza del ahorro en la educación de la infancia

El personal del archivo también se encarga de proponer acciones para optimizar, agilizar y facilitar la gestión del archivo. En este sentido el Archivo Histórico se encuentra inmerso en el establecimiento de un adecuado proceso de transferencia de la documentación desde los distintos departamentos hasta el Archivo Histórico. En lo referente al fondo fotográfico, se pretende establecer una política de transferencia desde el departamento encargado de la comunicación en la entidad como mayor productor de imágenes.

\section{2- La colección}

La fotografía es un documento visual fundamental para la historia de las Cajas de Ahorros y de la CECA y ha sido utilizada por estas entidades como uno de sus principales medios de expresión y comunicación. Estas fotografías son consideradas fuentes documentales que testimonian acontecimientos y eventos concretos de la actividad de la CECA y de las Cajas de Ahorros a lo largo de los años.

El fondo fotográfico de CECA-Cecabank posee una amplia y destacable colección de imágenes que cronológicamente abarca desde 1923, fecha en la que se data la fotografía más antigua custodia en el archivo y que muestra la presentación de los estatutos de la Caja de Ahorros y Monte de Piedad de Mataró, hasta la actualidad; y temáticamente no sólo recoge fotografías de la CECA, de las Cajas de Ahorros y de su Obra Social, sino que también encontramos imágenes digitales de carteles del Día Universal del Ahorro, trofeos, cuadros, huchas y otros objetos de promoción del ahorro, publicaciones, objetos de em- 
peño, carteles publicitarios, etc.

La procedencia de las fotografías se puede clasificar en dos orígenes, por un lado de la CECA y por otro de las Cajas de Ahorros.

Si atendemos a estos criterios de origen, las fotografías de la CECA componen un amplio conjunto de imágenes tomadas dentro de sus sedes durante actividades llevadas a cabo en las mismas. Estas fotografías son el reflejo gráfico de la gestión interna de la entidad o de la relación de la misma con las Cajas de Ahorros a lo largo de años. El grueso de estas imágenes corresponde en su mayor parte a los miembros de los órganos de gobierno, a destacados actos institucionales y a eventos nacionales e internacionales, como, por ejemplo, jornadas, firma de convenios, ruedas de prensa, congresos, etc.

Respecto al segundo grupo, se trata de un conjunto de imágenes que comprende fotografías de la actividad institucional de las Cajas de Ahorros y sobre todo de su Obra Social. Estas últimas constituyen sin duda un fiel reflejo de la importante labor socio-cultural llevada a cabo por estas entidades.

Atendiendo a estos dos orígenes se distinguen los dos fondos que componen la colección actual y que integran el futuro Archivo Fotográfico de CECACecabank.

\subsection{1- Fondo de la Confederación Española de Cajas de Ahorros (CECA)- Cecabank}

El fondo recoge distintos tipos de fotografías que pueden clasificarse de la siguiente manera:

- Edificios, oficinas, despachos y cajeros

- Presidentes y Directores

- Otros directivos de la entidad

- Órganos de Gobierno: miembros de la Asamblea General, del Consejo de Administración y de la antigua Comisión Permanente, del Comité de Control, etc.

- Logos y emblemas

- Actos conmemorativos: Día Universal del Ahorro, Día de la Sagrada Familia, homenajes, aniversarios, bodas de plata y oro, etc.

- Revista Ahorro

- Campañas de publicidad

- Huchas

- Eventos nacionales e internacionales: conferencias, congresos, reuniones, seminarios, jornadas de directivos y jornadas sectoriales, destacando los siguientes: 
-World Savings Banks Institute Congress (WSBI)

-European Savings Banks Group Congress (ESBG)

-Foro Cajas de Ahorros

-Encuentro del Sector Financiero

-Asambleas Generales de Cajas de Ahorros

-Asambleas Generales de Montes de Piedad

-Spain Inverstors Day

-Simposio Historia de Cajas de Ahorros

- Entrevistas, presentaciones a prensa, comparecencias y ruedas de prensa

- Premios, concursos y certámenes donde destacan: Hucha de Oro, concurso de cuentos, y el Arpa de Oro, concurso de música.

- Reportajes monográficos de servicios de la entidad

- Exposiciones:

-Siglo y Medio de Ahorro en España. 75 aniversario

-Microcréditos

-Montes de Piedad: tres siglos de historia

-Imágenes de una Buena Obra

-Carteles para el Ahorro

- Presentación de libros

- Propaganda, publicidad y promoción del ahorro en medios impresos: revistas y periódicos

- Federación nacional de asociaciones culturales y recreativas de empleados de Cajas de Ahorros (ACRECA)

Las imágenes del fondo fotográfico de la CECA han sido utilizadas para la edición de publicaciones y para la impresión de carteles publicitarios de exposiciones y otros eventos. En el caso de la labor editorial destaca la Revista Ahorro publicada desde 1955 hasta la actualidad, el libro Historia de la cooperación entre las Cajas de Ahorros (Comín-Comín, 2008) y los catálogos de exposiciones como, por ejemplo, Imágenes de una Buena Obra (CECA, 1998) y Siglo y Medio de Ahorro en España (CECA, 2003).

A continuación se describen y muestran algunas de las fotografías más representativas de los inicios. Destacan las imágenes de los primeros despachos y del primer edificio sede de la CECA, cuando era la Confederación Española de 
Cajas de Ahorros Benéficas (CECAB), situado en la calle de Alcalá, número 65 de Madrid y que fueron realizadas por el fotógrafo Alfonso cuyo laboratorio se encontraba en la calle Fuencarral de Madrid.

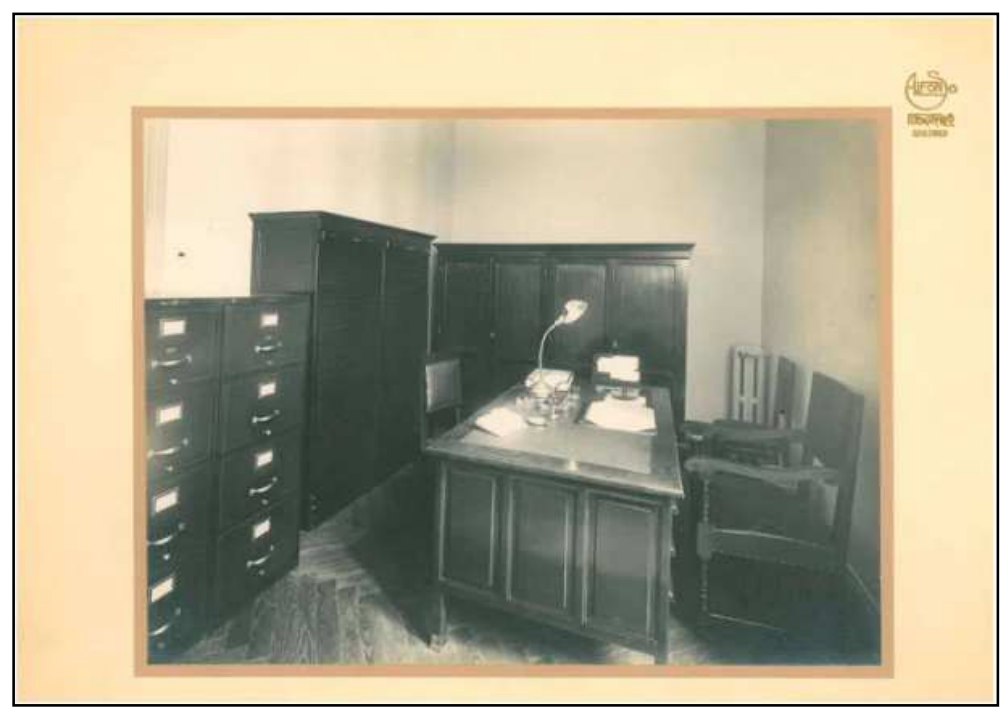

Por su carácter histórico, son relevantes las fotografías de los miembros de la CECAB, reunidos en asambleas y comisiones, y que fueron realizadas por Fotografía DUQUE emplazada en la calle Claudio Coello, número 71 de Madrid.

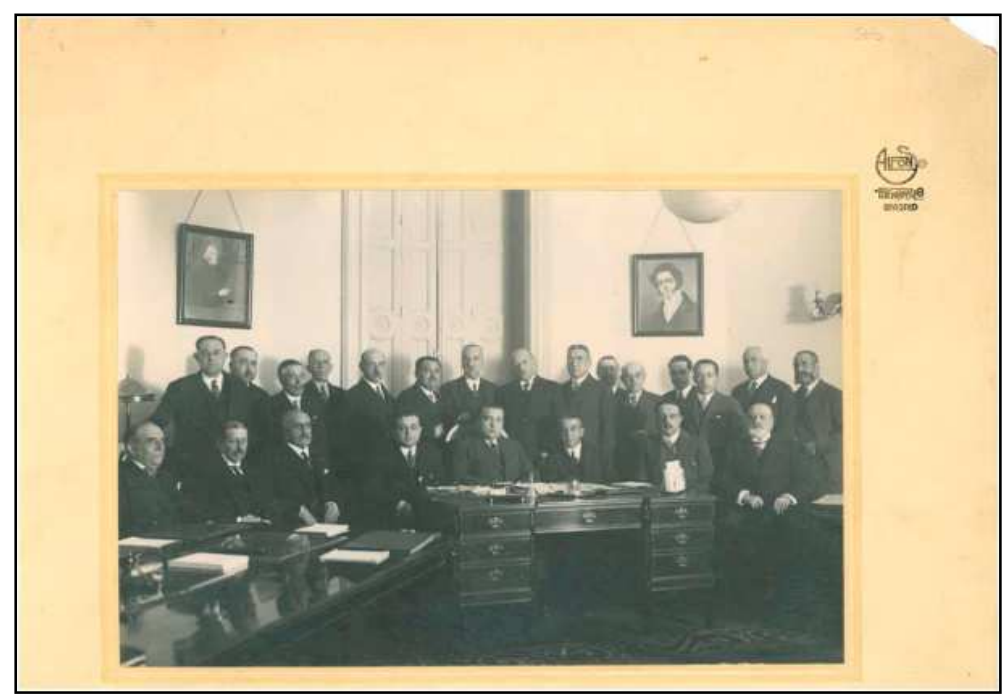

La CECA como asociación de Cajas de Ahorros y representante de las mismas también organizada eventos como, por ejemplo, la exposición mundial de huchas y de propaganda del ahorro con motivo del veinticinco aniversario de la CECAB celebrada en 1953. 
MEI, II, Vol. 5, no 9, pág. 114

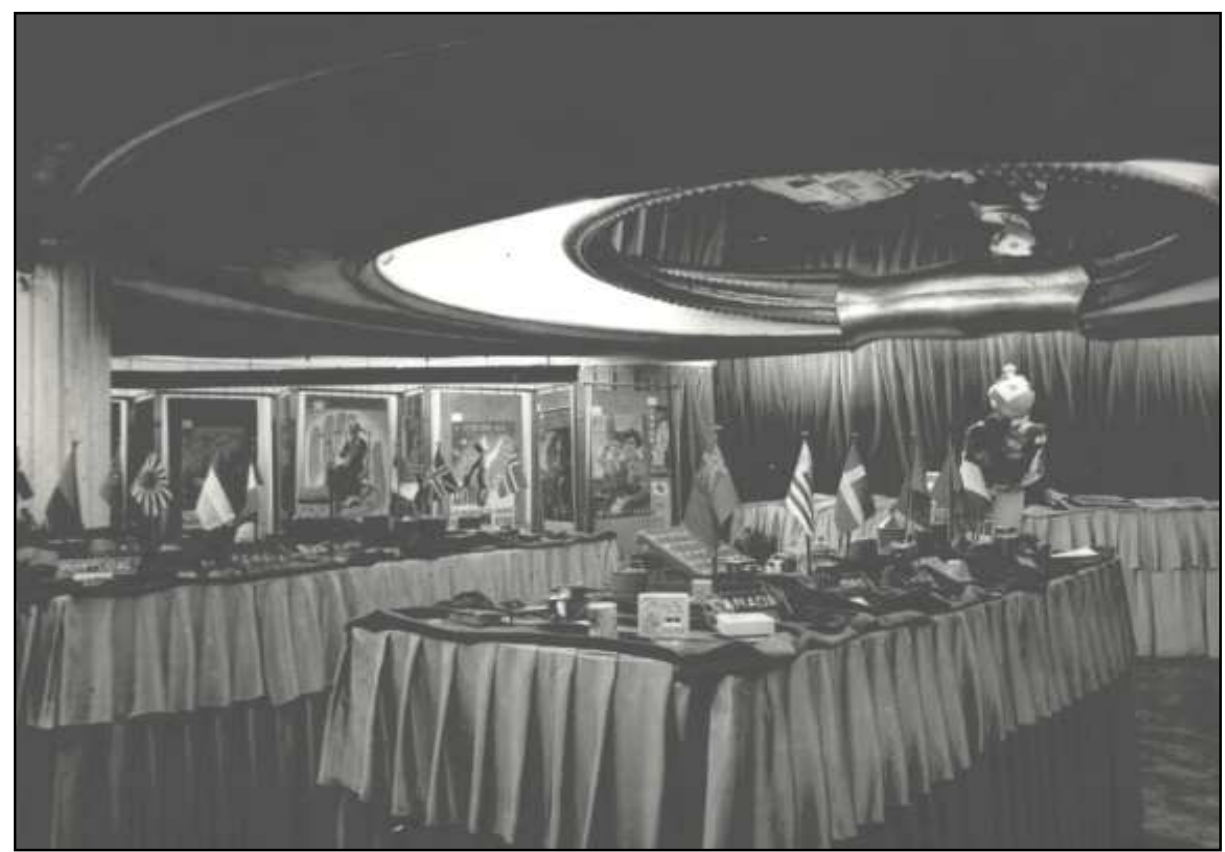

\subsection{2- Fondo de las Cajas de Ahorros}

El fondo de las Cajas de Ahorros contiene imágenes que pueden clasificarse en los siguientes grupos:

- Sedes centrales, oficinas, sucursales, despachos y sucursales móviles

- Presidentes y Directores

- Otros directivos

- Huchas de Cajas de Ahorros

- Cajeros automáticos

- Furgones blindados

- Campañas de publicidad

- Fundaciones

- Montes de Piedad

- Archivos Históricos de Cajas de Ahorros: edificios, salas, documentos, etc.

- Obra Social 
MEI, II, Vol. 5, no 9, pág. 115

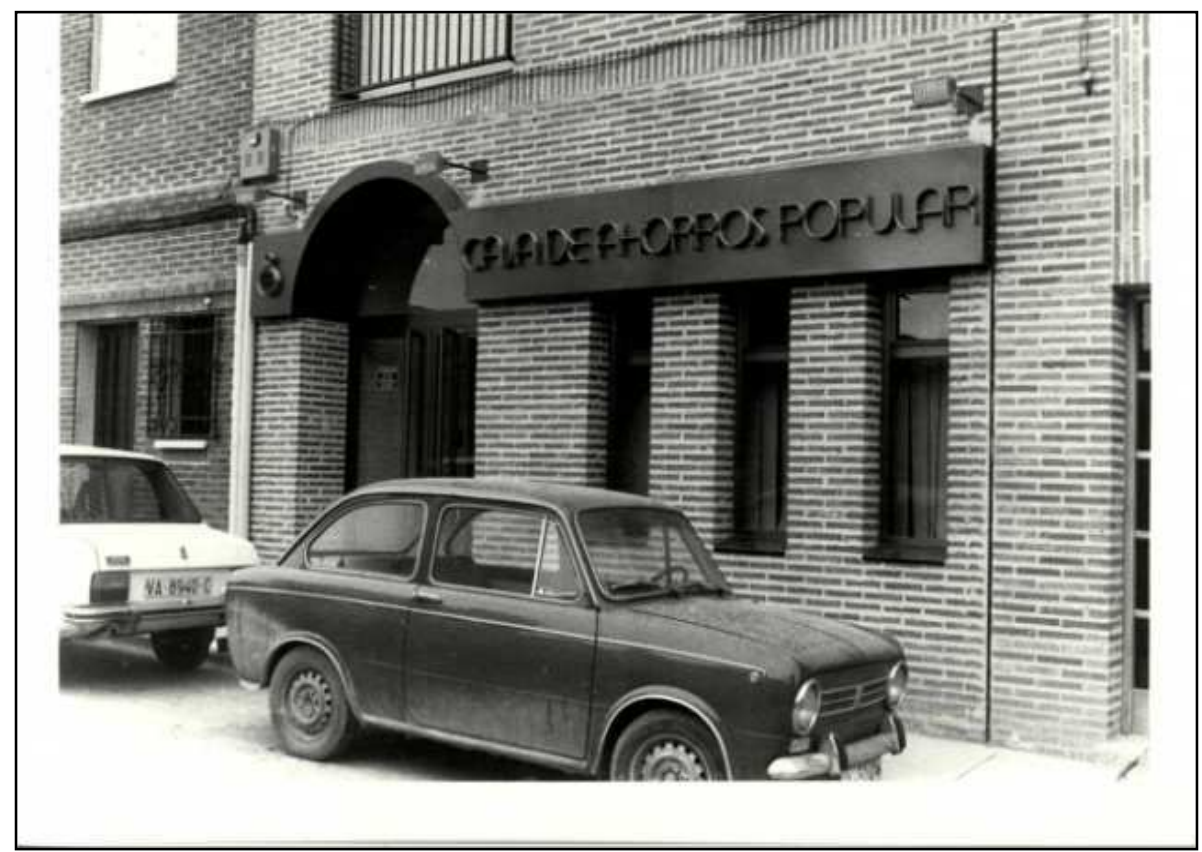

No obstante, las fotografías de las Cajas de Ahorros pertenecen en su mayor parte al último grupo, la Obra Social. Las Cajas de Ahorros desde su creación han combinado su actividad económica con la realización de actividades sociales (CECA, 1998), esto queda reflejado en las numerosas imágenes que se conservan en el fondo fotográfico y que pueden clasificarse en las siguientes aéreas sociales:

- Patrimonio histórico artístico y natural

- Actividades culturales y educativas

- Ocio y tiempo libre

- Asistencia social y sanitaria.

En lo relativo al primer punto, imágenes de la Obra Social dedicada al ámbito del patrimonio histórico artístico y natural, localizamos imágenes de edificios históricos y emblemáticos de gran valor artístico y arquitectónico. Muchos de estos edificios fueron o son actualmente sede de las Cajas de Ahorros y de sus Fundaciones, como las sedes institucionales de Casa Botines de Caja España en León (Bassegoda-Nonell et al., 2000) o el Palacio de Mayoralgo de la Caja de Extremadura (Rodríguez-Ibarra y Medina-Ocaña, 2004).

Gran parte de estas fotografías recogen también acciones destinadas a la conservación y mantenimiento del patrimonio arquitectónico español como, por ejemplo, catedrales e iglesias, museos, palacios y otros edificios emblemáticos. Asimismo se conservan imágenes de acciones dirigidas a la restauración de obras pictóricas y escultóricas. 
Por otro lado, existen fotografías de la Obra Social brindada a las actividades culturales y educativas tales como conciertos, becas de formación, actividades musicales, exposiciones, campañas escolares, danza, bibliotecas, actividades literarias, cursos y talleres de formación, teatro, visitas culturales, fiestas y homenajes, entrega de medallas, trofeos, diplomas y premios, concursos y certámenes.

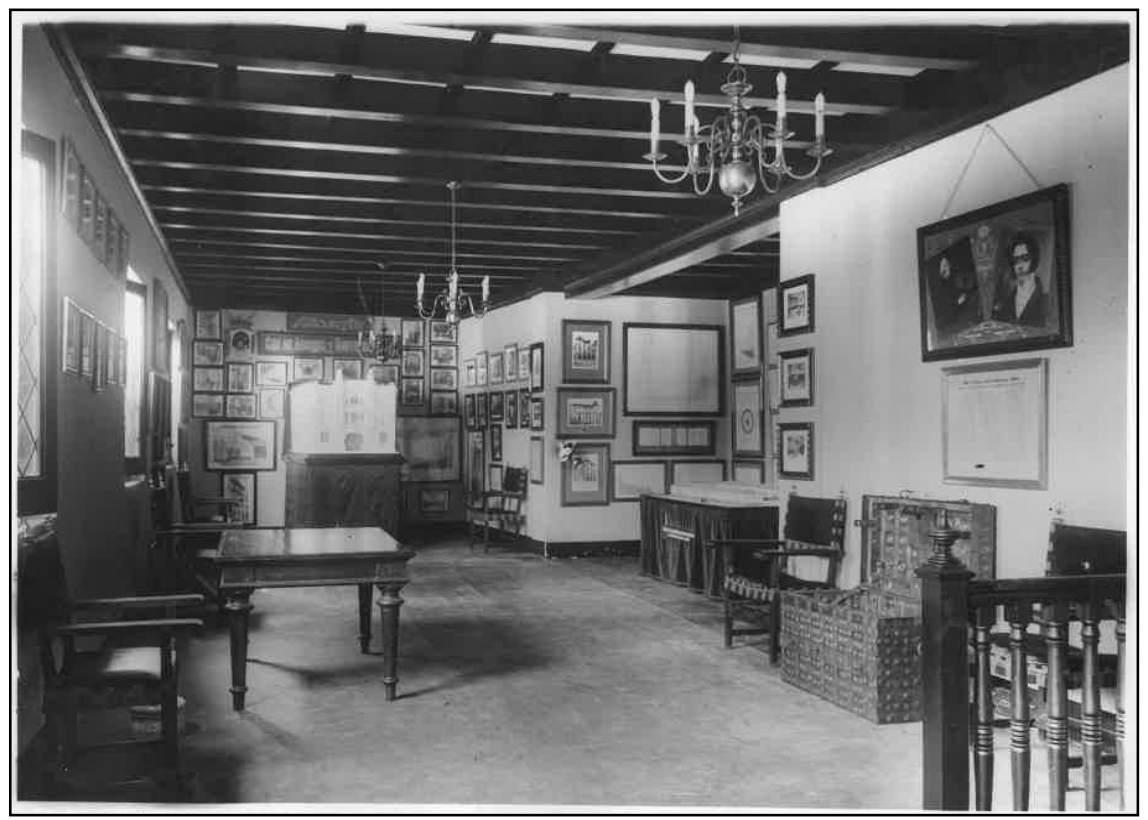

Respecto a las fotografías de la Obra Social dedicada al ocio y tiempo libre se localizan sobre todo imágenes vinculadas al deporte como, por ejemplo, competiciones y campeonatos, promoción y patrocinio de eventos deportivos y otras actividades ligadas a los siguientes deportes: ciclismo, vela, baloncesto y fútbol. También se conservan fotografías de residencias vacacionales, campañas navideñas, campamentos y colonias infantiles, viajes y excursiones.

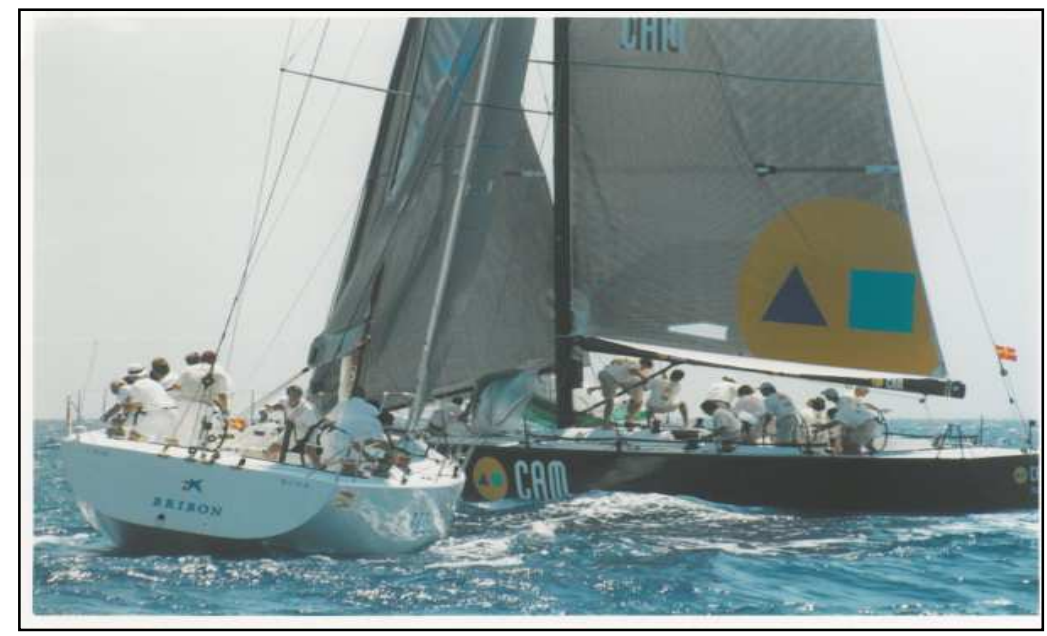


De fotografías relativas a la asistencia social y sanitaria encontramos ejemplos de centros, residencias y actividades destinados a la Tercera Edad, unidades asistenciales, programas asistenciales, actividades dedicadas a emigrantes y a la cooperación internacional para el desarrollo, centros para discapacitados, unidades móviles (ambulancias y camiones de bomberos), centros de acogida de menores y viviendas sociales.

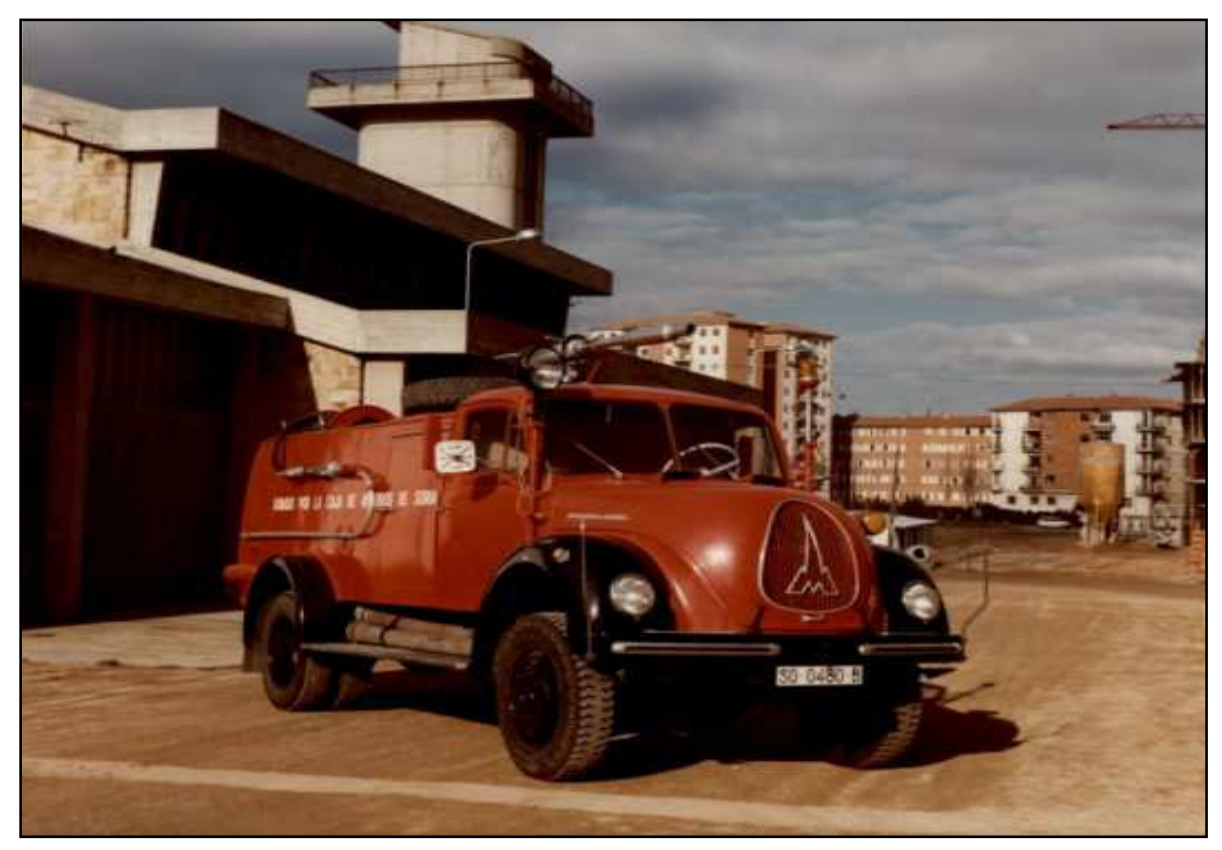

\section{5.- Fotógrafos de la CECA}

Los profesionales de la fotografía que han trabajado para la captación de imágenes de la CECA han sido fotógrafos particulares o fotógrafos de agencias. A continuación mostramos una relación de dichos profesionales con sus correspondientes periodos o años de dedicación ordenados cronológicamente y de otros fotógrafos de los que se poseen imágenes en el fondo. No obstante, se debe tener en cuenta que la lista no es completa ya que el fondo fotográfico aun está en pleno proceso de identificación y clasificación.

- Alfonso. Fuencarral, 8. Madrid (1928)

- DUQUE. Calle Claudio Coello 71, Madrid (1928)

- Foto-Inform BRANGULL. Paseo Prat de la Riba,18. Barcelona (1929)

- PIORTIZ. Cruz, 19. Madrid (1932)

- Francisco Ontañón (1970)

- Cifra (1978-1985) 
- Herzfoto (1978-1985)

- Europa (1978-1982)

- Europa Press (1978)

- Peter Beckmann (1978)

- Santiago García (1986-1996)

- EFE (1986-1995)

- Dalda (1995)

- Aulocolor (1995)

- Fotógrafo de la Casa Real (1995)

- Eduardo Méndez (1997-1998)

- Carmen Barrio (-1999)

- Antonio Lago (1999)

- Álvaro Benítez (1999)

- Rafa Saiz (2000)

- Federico Grau (2001-)

\section{6.- Conclusiones}

El Archivo Histórico de CECA-Cecabank considera la fotografía como un documento histórico que, como tal, nos muestra la historia a través de la imagen que representa y constituye una fuente de memoria. En estos aspectos radica la importancia que el Archivo Histórico otorga a su fondo fotográfico como parte fundamental para la historia de las Cajas de Ahorros y de la CECA.

La fotografía ha sido utilizada por la CECA y por las Cajas de Ahorros como uno de sus principales medios de expresión y comunicación y por ello es considerada una fuente documental que testimonia acontecimientos y eventos concretos de la actividad de la CECA y de las Cajas de Ahorros a lo largo de los años. Estas imágenes no sólo son parte importante de la memoria histórica de un sector de gran relevancia en el mundo financiero sino que también muestran aspectos de la vida política, cultural y social de España.

El Archivo Histórico de CECA-Cecabank tiene ante sí el reto de constituir y consolidar el Archivo Fotográfico de CECA-Cecabank y del sector Cajas de Ahorros. La creación de este archivo supondrá la puesta a disposición de los investigadores, a nivel nacional e internacional, y del público en general de una fuente de información de gran valor para conocer la historia de la CECA y la trayectoria histórica e importancia de las Cajas de Ahorros en España. 


\section{7.- Referencias bibliográficas}

Arroyo-Martín, J.V. 2005. Archivo Histórico BBVA: memoria histórica de 150 años de banca y economía en España. Bilbao: Archivo Histórico BBVA.

Bancaixa. 2011. Archivo Bancaja: de la gestión económica a la memoria social valenciana. [Consulta: 3 Noviembre 2014]. Disponible en: http://repositori.uji.es/xmlui/bitstream/ handle/10234/28930/Archivo+Bancaja_+Guerrero_Capellino.pdf?seque

Bassegoda-Nonell, J., Giralt-Miracle, D., Carriedo-Tejedo, M., Compadre-Díez, F., Díez-Sáenzde-Miera, M., García-Zurdo, L., Castrillo, J.F., Azconegui-Morán, F. y Miguélez-Castellanos, A. 2000. El edificio Gaudí de León: Casa Botines (sede social de Caja España). $2^{\mathrm{a}}$ ed. León: Caja España de Inversiones.

Caja de Ahorros del Mediterráneo (CAM). 2005. Las raíces de la CAM. Alicante: Caja de Ahorros del Mediterráneo.

Carriedo-Tejedo, M. y Titos-Martínez, M. 2005. Montes de Piedad: tres siglos de historia. Madrid: CECA.

Carriedo-Tejedo, M. y Rubio-Valle, Y. 2008. El Archivo Histórico de Caja España, Revista de Caja España, no $45,62-65$.

Comín-Comín, F. 2008. Historia de la cooperación entre las Cajas: la Confederación Española de Cajas de Ahorros (1928-2007. Madrid: Alianza.

Confederación Española de Cajas de Ahorros (CECA). 1980. 10 años de publicidad corporativa en las cajas de ahorros. Madrid: CECA.

Confederación Española de Cajas de Ahorros. 1998. Imágenes de una buena obra: la obra social de las cajas de ahorros: [Biblioteca Nacional, Madrid, 17 diciembre de 1998-10 de enero de 1999. Madrid: CECA.

Confederación Española de Cajas de Ahorros. 2003. Siglo y medio de ahorro en España: exposición 16 de septiembre-31 de octubre de 2003. Madrid: CECA.

Fundación de Cajas de Ahorros (FUNCAS). 2005. Carteles para el Ahorro: 1880-1975: apéndice 1976-2004: lugar de exposición: Confederación Española de Cajas de Ahorros. Madrid: FUNCAS.

Gato-Gutiérrez, M., Benlloch, P., Maynés, P., Aleixandre-Benavent, R., González, L.M., FerrerSapena, A., Peset, F. 2011. Colecciones de fotografía en España: propuesta del directorio fotográfico en España (dFoto). En: 11es Jornades Antoni Varés. Imatge i recerca. 18 Noviembre, Girona

Lasso-de-la-Vega, J. 1971. Ensayo para la aplicación del sistema decimal universal a los archivos de las cajas de ahorros. Boletín de Documentación del Fondo para la Investigación Económica y Social, vol. $3, \mathrm{n}^{\mathrm{o}} 3,188-199$.

Rodríguez-Ibarra, J.C. y Medina-Ocaña, J. 2004. El Palacio de Mayoralgo: sede institucional de la Caja de Extremadura. Cáceres: Caja de Extremadura.

Sánchez-Vigil, J.M. y Salvador-Benítez, A. 2013. Documentación fotográfica. Barcelona: UOC. 
MEI, II, Vol. 5, no 9, pág. 120

Titos-Martínez, M. 1976, Aportación de los fondos documentales de las Cajas de Ahorros y Montes de Piedad a la Historia Social y Económica. Boletín de Documentación del Fondo para la Investigación Económica y Social, vol. 8, nº 3, 371-381.

Tortella, T. 1983, Los archivos bancarios en España. Boletín ANABAD, vol. 33, nº 1, 27-42.

Tortella, T. 1989. Los archivos bancarios españolas en la actualidad. Boletín ANABAD, vol. 39, $n^{0} 3-4,511-518$.

Tortella, T. 2010. El Banco de España desde dentro: una historia a través de sus documentos. Madrid: Banco de España.

Vellosillo, F. 1970. El Archivo y las Memorias de la Caja de Ahorros y Monte de Piedad de Madrid. Boletín de Documentación del Fondo para la Investigación Económica y Social, vol. 2, no 1 . 